\title{
Agent-based modelling and inundation prediction to enable the identification of businesses affected by flooding
}

\author{
G. Coates ${ }^{1}$, G. I. Hawe ${ }^{2}$, N. G. Wright ${ }^{3} \&$ S. Ahilan ${ }^{3}$ \\ ${ }^{1}$ Durham University, UK \\ ${ }^{2}$ University of Ulster, $U K$ \\ ${ }^{3}$ University of Leeds, UK
}

\begin{abstract}
Flooding continues to cause significant disruption to individuals, organisations and communities in many parts of the world. In terms of the impact on businesses in the United Kingdom (UK), flooding is responsible for the loss of millions of pounds to the economy. As part of a UK Engineering and Physical Sciences Research Council funded project on flood risk management, SESAME, research is being carried out with the aim of improving business response to and preparedness for flood events. To achieve this aim, one strand of the research is focused on establishing how agent-based modelling and simulation can be used to evaluate and improve business continuity. This paper reports on the development of the virtual geographic environment (VGE) component of an agent-based model and how this has been combined with inundation prediction to enable the identification of businesses affected by flooding in any urban area of the UK. The VGE has been developed to use layers from Ordnance Survey's MasterMap ${ }^{\circledR}$, namely the Topography Layer, Integrated Transport Network ${ }^{\mathrm{T}} \mathrm{M}$ Layer and Address Layer 2. Coupling the VGE with inundation prediction provides credibility in modelling flood events in any area of the UK. An initial case study is presented focusing on the Lower Don Valley region of Sheffield leading to the identification of businesses impacted by flooding based on a predicted inundation. Further work will focus on the development of agents to model and simulate businesses during and in the aftermath of flood events such that changes in their behaviours can be investigated leading to improved operational response and business continuity.

Keywords: floods, businesses, agent-based modelling and inundation prediction.
\end{abstract}




\section{Introduction}

In recent years, many parts of the world have experienced and suffered from severe flooding which continues to cause significant disruption to individuals, organisations and communities. In terms of the impact on UK businesses, research conducted by the Environment Agency (EA) has estimated the financial cost of floods in 2012 as being nearly $£ 600$ million [1]. Further, the EA has indicated flooding cost an average of $£ 60,000$ for every business affected. Such significant economic loss has led to flood risk management becoming high on the political agenda. Consequently, means of reducing the economic impact of interruptions attributable to flooding at the business level, and thus more widely, are receiving growing attention. Effective business continuity management $(\mathrm{BCM})$ is recognised as one means of reducing the effect of flooding on business operations and enabling a more rapid return to normality. Indeed, BCM is viewed as an important tool for business survival in the face of a range of disruptive events [2, 3], including flooding, and a key part of any successful flood response [4]. The International Organization for Standardization's ISO 22301, which is related to BCM, is described as the requirements which will help organisations to be better prepared and handle disruptions of any type [5]. Despite the existence of such standards, in the UK, organisational engagement with business continuity remains low with less take-up by Small and Medium Enterprises (SMEs) relative to larger businesses and public sector bodies [6, 7].

The Engineering and Physical Sciences Research Council funded SESAME project is related to organisational operational response and strategic decision making for long term flood preparedness in urban areas [8]. The project aims to create a unified framework of academic knowledge that can be used to influence the behaviours of businesses, particularly SMEs, faced with flooding and flood risk. This framework will assist businesses in understanding how they might reduce the disruption and economic loss associated with flood events thus strengthening their resilience to flooding and that of the wider economy. To realise this aim, four interdisciplinary research objectives are being pursued: (i) achieve a better understanding of how businesses behave in the immediate and longer term aftermath of flood events; (ii) establish how agent-based modelling and simulation can be used to assess the behaviours of different types of businesses at risk of flooding; (iii) assess the impacts of flooding on economic systems both within and beyond the immediately affected urban area and explore how changes in businesses' behaviour could influence these impacts; (iv) develop and evaluate approaches promoting organisational behaviour change and adaptive learning throughout the flood cycle. In order to achieve these research objectives, the SESAME project brings together the academic fields of business continuity management, agent-based modelling and simulation, flood modelling, economic modelling and the social/behavioural sciences. This paper focuses on the development of the virtual geographic environment (VGE) component of an agent-based model along with how this has been brought together with inundation prediction, via flood modelling, to identify businesses affected by flooding in any urban area of the UK. 


\section{Related work}

In the disaster management domain, research in the area of agent-based modelling and simulation has focused on emergency response to major natural and manmade events with agents representing emergency responders and/or members of the public [9-12]. In relation to flood risk management, agent-based models have usefully been employed to model evacuation strategies involving agents representing members of the public $[13,14]$. However, despite the concept of using agent-based modelling in business and organisation problems [15-22], there is lack of research in the context of modelling businesses faced with the challenges of ensuring business continuity when subjected to flooding. This current dearth of research in agent-based modelling and simulation in the context of business response to flooding offers scope for significant contributions to knowledge to be made in relation to (i) identifying the specific businesses affected by a flood event in a particular geographical area which can then be modelled as agents, (ii) modelling these business agents' actions and interactions when responding to flood events based on field data gathered through interviews with businesses at risk of flooding and/or which have experience of flooding, and (iii) performing what-if analysis via agent-based simulations of businesses' responses to flood events in order to establish the effect of changes in their behaviour and different approaches taken such as adhering to flood plans.

\section{Agent-based modelling and flood modelling}

Agent-based modelling and simulation, coupled with inundation prediction via flood modelling, is being used to enable the investigation of the organisational behaviour of businesses when faced with flood events. An overview of the modelling and simulation framework is presented in Figure 1.

The aim of this framework is to establish how agent-based modelling and simulation can be used to improve organisational business continuity of different types of UK businesses when responding to flooding by means of representing their attributes and simulating their actions, interactions and dynamic behaviours. Stage 1 of the framework involves developing the agent-based model's VGE, which is able to combine Ordnance Survey (OS) information with flood model output, in Stage 2, in order to identify the businesses affected by flooding. Flood model output can be static in the sense of providing a single-shot footprint of the flood water in a geographical area, or dynamic in that the flood inundation varies with time thus bringing a temporal aspect to simulations performed in Stage 5 . Stage 3 relates to developing agents to model businesses in terms of their attributes, behaviour, actions and interactions in response to flood events. Stage 4 involves setting-up an agent interaction framework to enable simulations to be performed, in stage 5 , thus informing businesses how they might change their behaviour to better prepare for and respond to future flood events. 


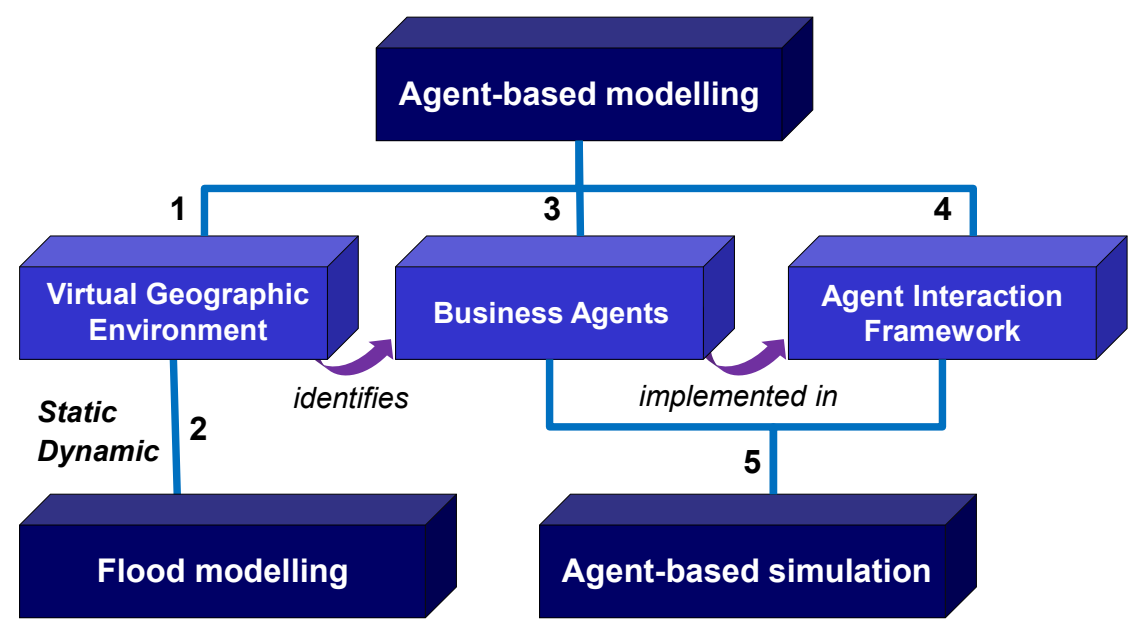

Figure 1: Overview of modelling and simulation framework.

\subsection{Virtual geographic environment}

Software has been developed to model a VGE of any region of the UK thus providing the flexibility to credibly model flood events in any urban area and to identify the businesses affected in that area. To achieve this aim, three layers of OS MasterMap ${ }^{\circledR}$ have been used [23]. Prior to indicating the information within these layers relevant to the application of this work, it is appropriate to present Figure 2, which shows the VGE for a case study area currently under consideration, namely the Lower Don Valley region of Sheffield.

This region was identified as a suitable case study due to its high concentration of SMEs from a range of sectors allied with their experience of

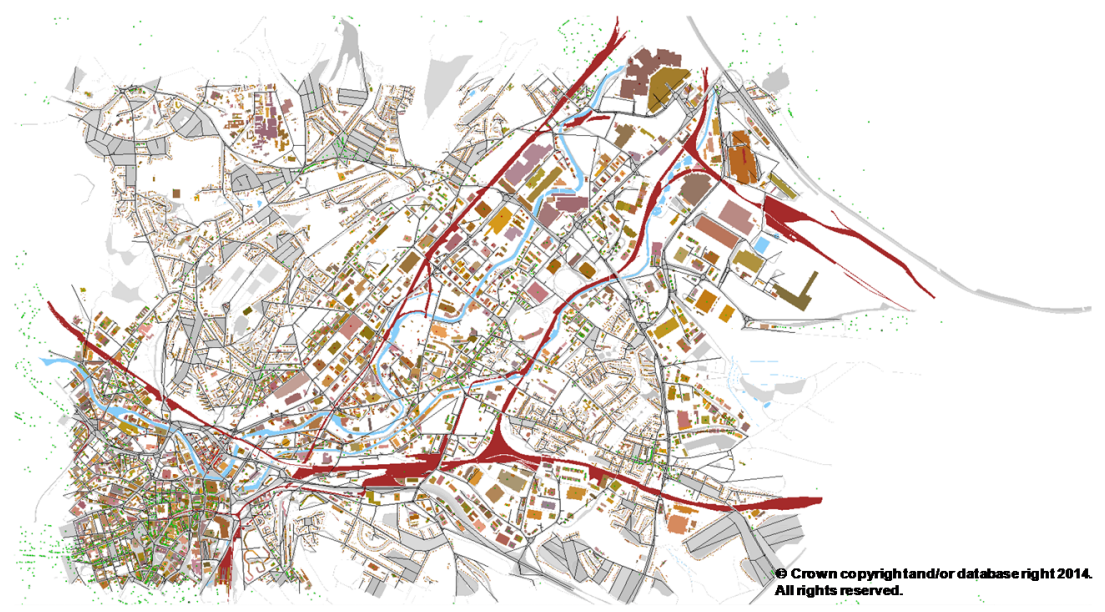

Figure 2: VGE for the Lower Don Valley region of Sheffield. 
significant flooding. In June 2007, approximately $100 \mathrm{~mm}$ of rainfall fell in 24 hours in the Lower Don Valley region having a devastating impact on more than 1000 businesses including key manufacturing companies with one suffering over $£ 15$ million worth of damage [24].

In order to construct a VGE, use is made of OS MasterMap's Topography Layer, Integrated Transport Network ${ }^{\mathrm{TM}}$ Layer and Address Layer 2 to define and populate the area under consideration with the relevant geographical information. For any given geographical area: the Topography Layer is used to provide information on individual buildings; the Integrated Transport Network ${ }^{\mathrm{TM}}$ (ITN) Layer provides information on the road network; the Address Layer 2 provides information on commercial properties including the precise location and the identification of the associated building in the Topography Layer and road link in the ITN Layer. Information in the Topography Layer and ITN Layer from EDINA Digimap $^{\circledR}$ is freely available to academic institutions; however research agreements with OS are required to obtain and use Address Layer 2 information.

\subsection{Coupling the virtual geographic environment with flood modelling}

For flood modelling, OS data sets are also required for the geographical area under consideration, in this case the Lower Don Valley region of Sheffield. The data sets obtained covered rivers, building features and a Digital Terrain Model. From these data sets, the River Don's centre line was delineated, the adjacent floodplains were identified and a Geographic Information System (GIS) model was built. Further, data from three hydrometric gauges in the River Don, near the study region, were used to provide maximum water levels, which were then interpolated across the region identified using the GIS model. These maximum water depths at each $(x, y)$ location within the area under consideration were input to the VGE, which is shown in Figure 3 for Sheffield's Lower Don Valley region with the flood extent included.

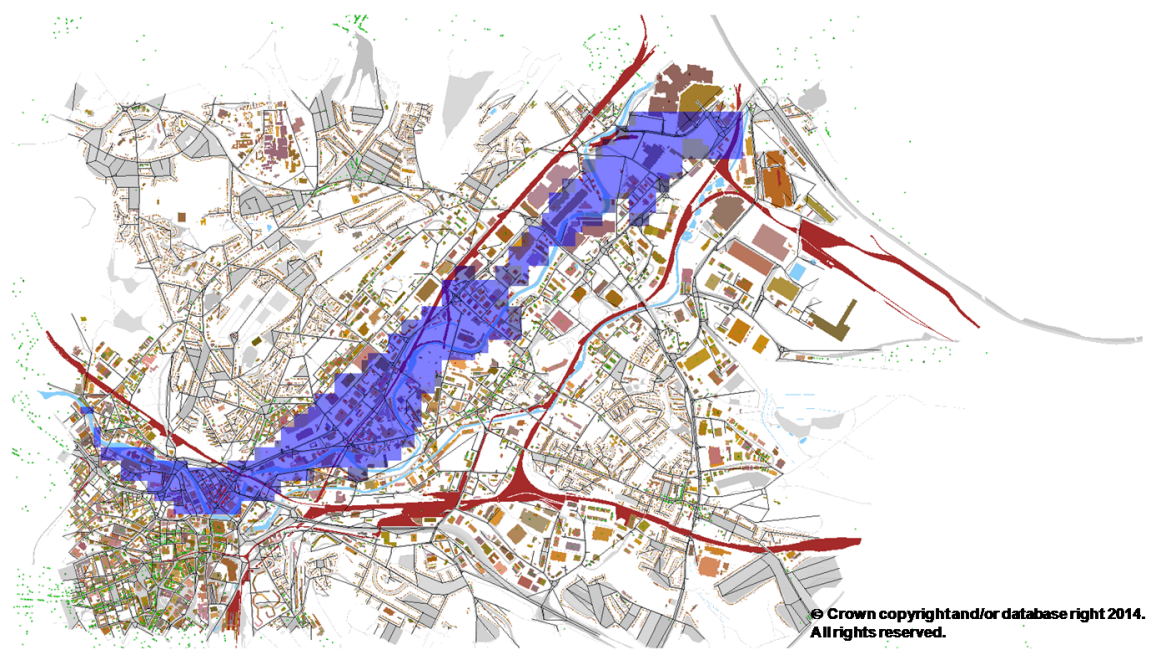

Figure 3: VGE for the Lower Don Valley region of Sheffield with flood extent. 
In Figure 3, the flood extent is represented coarsely due to being based on a simplistic inundation prediction analysis. However, this representation is adequate for the purpose of the initial case study. Future work will involve the method used to determine maximum water depths being improved and model data from the Lower Don Valley region being obtained from the EA.

\subsection{Business agents}

\subsubsection{Identification of businesses affected by flooding}

Once the geographical information from the three layers of OS MasterMap ${ }^{\circledR}$ for a specific area has been inputted to the software to create the VGE, along with associated flood model output, a database is created holding information associated with businesses in the flood affected area, which can be interrogated. For example, businesses identified can be filtered according to industry type, and then defined as the businesses to be modelled as agents. In addition to showing the extent of flood water displayed in the VGE for the case study area, Figure 4 indicates the location of each business using a circle symbol, which is colourcoded according to whether their associated building is flooded (red), or their building is not flooded but their associated road link is flooded (orange), or neither their associated building nor road link is flooded (green).

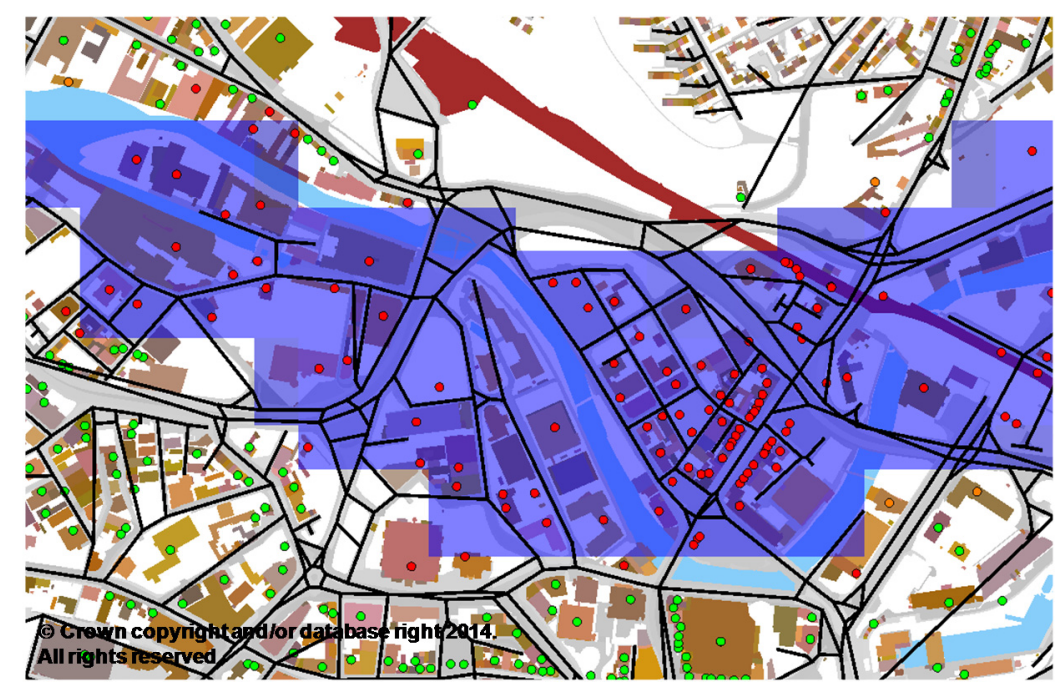

Figure 4: Identification of organisations affected by flooding.

Using the database created for the Lower Don Valley region of Sheffield, 4037 businesses were identified as being within the bounded area considered with 531 of those businesses affected directly by flooding based on the inundation prediction. In this context, "affected directly by flooding" signifies that both the building, and the road link associated with the building, of a 
particular business were under a depth of water greater than or equal to $1 \mathrm{~mm}$. Based on the inundation prediction, the depth of flood water can be established for every business. For the Lower Don Valley region of Sheffield, Table 1 presents a profile of the number of businesses' buildings and road links affected by flooding in relation to depth of flood water.

Table 1: Number of businesses' building and road link affected by flooding.

\begin{tabular}{|c|c|c|}
\hline $\begin{array}{c}\text { Water depth, } \\
\mathrm{d}\end{array}$ & $\begin{array}{c}\text { Number of businesses' } \\
\text { building affected by } \\
\text { flooding }\end{array}$ & $\begin{array}{c}\text { Number of businesses' } \\
\text { road link affected by } \\
\text { flooding }\end{array}$ \\
\hline $\mathrm{d}<1 \mathrm{~m}$ & 64 & 40 \\
\hline $1 \mathrm{~m} \leq \mathrm{d}<2 \mathrm{~m}$ & 150 & 141 \\
\hline $2 \mathrm{~m} \leq \mathrm{d}<3 \mathrm{~m}$ & 108 & 138 \\
\hline $\mathrm{d} \geq 3 \mathrm{~m}$ & 209 & 212 \\
\hline
\end{tabular}

Using OS MasterMap ${ }^{\circledR}$ Address Layer 2's Valuation Office Agency Nondomestic Rates Special Category (SCat) code, of which there are 360 categories for classifying businesses, the most prominent types of businesses affected by flooding in Sheffield's Lower Don Valley region are listed in Table 2. While the SCat classification is broad, importantly, Address Layer 2 provides the name of each individual business allowing an accurate profile to be constructed in terms of specific businesses affected by flooding. For example, under the category 'Factories, Workshops and Warehouses', heavy engineering businesses dominate with a variety of companies manufacturing a range of products such as specialist metals, wire meshes and weighing equipment. Also, in the 'Offices' category, businesses include recruitment firms, property agents and event organisers.

Table 2: Classification of businesses affected by flooding.

\begin{tabular}{|l|c|c|}
\hline SCat description & $\begin{array}{c}\text { SCat } \\
\text { code }\end{array}$ & $\begin{array}{c}\text { Number of } \\
\text { businesses }\end{array}$ \\
\hline Factories, Workshops and Warehouses & 96 & 146 \\
\hline Offices & 203 & 97 \\
\hline Shops & 249 & 46 \\
\hline
\end{tabular}

In addition to the business categories indicated in Table 2, 45 other business types were affected by flooding such as vehicle repair workshops, food stores, scrap metal yards, garages, car showrooms, cafes and takeaway food outlets.

It is recognised that as well as the SCat code in Address Layer 2, other business classifications exist including Base Function (1500 functions available), National Land Use Database Code (41 groups available) and Valuation Office Agency Non-domestic Rates Primary Description (PDesc) Code (8 divisions and 108 sub-divisions available). Further, other strands of the SESAME project related to business continuity and economic modelling employ the United Nations Statistics Division's International Standard Industrial Classification 
(ISIC) of All Economic Activities, Rev.4, (21 high level activities and 99 subactivities) and the Cambridge Econometrics' Multisectoral Dynamic Model (MDM-E3) of the UK economy (46 industry types) respectively. Mapping between these different classifications will be required once agent models are developed in preparation for agent-based simulations to be performed.

\subsubsection{Preliminary work on modelling business agents}

Within the SESAME project, modelling business agents is being driven by information extracted from transcripts of interviews with businesses at risk of flooding and/or which have experienced flooding. To date, the focus has been on businesses in the Lower Don Valley area of Sheffield given that in this geographical area a significant number of businesses experienced flooding in 2007. A series of interviews has commenced involving businesses from a range of sectors such that the attributes and behaviours to be defined for agents, including their actions and interactions in response to flood events, are representative of those organisations. Information extracted relates to attributes such as business function, property, customers and suppliers. In terms of behaviour, information extracted is based on experience of major disruptions, in particular flooding during and post event, plans for business continuity both pre and post event, and impact on business operations. Initial interviews have revealed that SMEs appear not to rely on formal structures or have flood plans in place should such a disruptive event occur. Rather, these businesses deal with emergency situations, such as flooding, through improvisation.

\section{Conclusions and future work}

Flooding is the most common and widespread type of natural disaster in the UK. For businesses, flooding poses a significant threat which can result in interruption to operations and financial losses, as well as damage to property. Thus, when faced with flooding and its effects, a business must know how to ensure it is able to continue performing critical activities and maintain the resources required to deliver its products and services in addition to protecting staff and premises, and maintaining stock. By doing so, business disruption can be reduced and recovery can be brought about more quickly.

The main aim of the SESAME project is to improve business response to and preparedness for flood events. Research carried out to date on one strand of the project has led to the capability to model any geographical urban area in the UK and, based on inundation prediction via flood modelling, identify businesses affected by flooding. An initial case study of the Lower Don Valley region of Sheffield has enabled an accurate profile of businesses affected by flooding to be constructed, with each business identified to be modelled as an agent. Future work will focus on the design and development of business agents and an agent interaction framework to enable simulations to be performed of businesses' responses to flood events. More interviews will be held with a variety of businesses in other geographical areas of the UK designated at risk of flooding and/or which have experience of different types of flooding (fluvial, pluvial and 
coastal), thus informing the attributes and behaviour of business agents. Also, these interviews will be used to elicit types of potential behaviour changes a business could make in terms of how it prepares for and/or responds to flood events, which could subsequently be investigated using agent-based simulation. Depending on the type of business being modelled, examples of such changes could relate to: flood insurance; registering to receive EA flood warnings; relocating key operations; training staff; installing flood barriers; making premises more resilient to flooding using water resistant materials; developing a flood plan; backing-up customer databases and electronic files; moving storage areas out of reach of flood waters; being able to quickly move equipment, computers, furniture, paper files, electrical items above ground level or to an upper level of the building if possible; identifying alternative supply and distribution routes; developing relationships with service and supply companies in advance of flooding such that essential work can be undertaken rapidly to quicken recovery and reduce business interruption.

\section{Acknowledgement}

The authors gratefully acknowledge the funding provided by the UK's EPSRC under grant EP/K012770/1.

\section{References}

[1] http://www.environment-agency.gov.uk

[2] Elliott, D., Herbane, B. \& Swartz, E., Business Continuity Management, Routledge: London, 2001.

[3] Herbane, B., The evolution of business continuity management: A historical review of practices and drivers, Business History, 52(6), pp. 978-1002, 2010.

[4] Pitt, M., The Pitt Review: Lessons learned from the 2007 floods, Cabinet Office, 2008.

[5] http://www.iso.org

[6] Musgrave, B. \& Woodman, P., Weathering the Storm: The 2013 Business Continuity Management Survey, Chartered Management Institute: London, 2013.

[7] Herbane, B., Small business research: Time for a crisis-based view, International Small Business Journal, 28(1), pp. 43-64, 2010.

[8] Coates, G., Hawe, G.I., McGuinness, M., Wright, N.G., Guan, D., Harries, T. \& McEwen, L., A framework for organisational operational response and strategic decision making for long term flood preparedness in urban areas, Proceedings of the 3rd International Conference on Disaster Management, 2013.

[9] Kitano, H. \& Tadokoro, S., RoboCup Rescue: A Grand Challenge for Multiagent and Intelligent Systems, Artificial Intelligence Magazine, 22(1), pp. 39-52, 2001. 
[10] Mysore, V., Narzisi, G. \& Mishra, B., Agent Modeling of a Sarin Attack in Manhattan, Proceedings of the 1st International Workshop on Agent Technology for Disaster Management in the 5th International Conference on Autonomous Agents and Multi-Agent Systems, pp. 108-115, 2006.

[11] Bellamine-Ben Saoud, N., Ben Mena, T., Dugdale, J., Pavard, B. \& Ben Ahmed, M., Assessing large scale emergency rescue plans: an agent based approach, International Journal of Intelligent Control and Systems: Special Issue on Emergency Management Systems, 11(4), pp. 260-271, 2006.

[12] Hawe, G.I., Wilson, D.T., Coates, G. \& Crouch, R.S., Investigating the Effect of Overtriage on Hospital Arrival Times of Critically Injured Casualties during a Major Incident using Agent-Based Simulation, Proceedings of the 6th International Conference on Soft Computing and Intelligent Systems and the 13th International Symposium on Advanced Intelligent Systems, 2012.

[13] Liu, Y., Okada, N., Shen, D. \& Li, S., Agent based flood evacuation simulation of life-threatening conditions using Vitae system model, Journal of Natural Disaster Science, 31(2), pp. 33-41, 2009.

[14] Dawson, R., Peppe, R. \& Wang, M., An agent based model for risk-based flood incident management, Natural Hazards, 59(1), pp. 167-189, 2011.

[15] Nagendra Prasad, M.V. \& Chartier, D.A., Modeling Organizations using Agent-based Simulations, Proceedings of the Workshop on Agent simulation: Application, Models \& Tools, pp. 54-66, 1999.

[16] Gilbert, N. \& Terna, P., How to Build and Use Agent-based Models in Social Sciences, Mind \& Society, 1, pp. 57-72, 2000.

[17] Bonabeau, E., Agent-based modeling: Methods and techniques for simulating human systems, Proceedings of the National Academy of Sciences of the United States of America, 99(3), pp. 7280-7287, 2002.

[18] North, M. J. \& Macal, C.M., Managing business complexity: discovering strategic solutions with agent-based modeling and simulation, Oxford University Press: Oxford, 2007.

[19] Gilbert, N., Agent-based models, In: UNSPECIFIED Quantitative Applications in the Social Sciences, Sage Publications Inc., 2007.

[20] Dignum, V. \& Tick, C., Agent-based Analysis of Organizations: Formalization and Simulation, Proceedings of the IEEE/WIC/ACM International Conference on Intelligent Agent Technology, pp. 244-247, 2007.

[21] Wilkinson, I.F., Marks, R.E. \& Young, L., Toward Agent-based Models of the Development and Evolution of Business Relations and Networks, In Unifying Themes in Complex Systems - Volume VI: Proceedings of the 6th International Conference on Complex Systems, ed. Ali A. Minai, Dan Braha \& Yaneer Bar-Yam, Springer, New York, pp. 414-421, 2010.

[22] Fioretti, G., Agent-Based Simulation Models in Organization Science, Organizational Research Methods, 16(2), pp. 227-242, 2013.

[23] http://www.ordnancesurvey.co.uk

[24] Environment Agency, Review of 2007 summer floods, December 2007. 